\title{
Sobre laboratórios e jardins
}

DoI

http://dx.doi.org/10.11606/ 2179-0892.ra.2017.137325

\author{
Giovana Acacia Tempesta \\ - Universidade de Brasília | Brasília, DF, Brasil \\ $\boldsymbol{\nabla}$ giovana.tempesta@gmail.com
}

\section{MATTINGLY, Cheryl. 2014. Moral Laboratories. Family Peril and the Struggle for a Cood Life. Oakland, University of California Press, 280 pp.}

Moral Laboratories. Family Peril and the Struggle for a Good Life é o segundo resultado de fôlego ${ }^{1}$ de uma pesquisa realizada por uma equipe multidisciplinar, coordenada pelas antropólogas Cheryl Mattingly e Mary Lawlor, que, entre os anos de 1997 e 2011, focalizou famílias afro-americanas pobres vivendo em Los Angeles, Estados Unidos. Este livro é de autoria de Mattingly e se concentra em histórias de cinco famílias, embora a pesquisa tenha contemplado cerca de cinquenta. $A$ reflexão é elaborada em torno da indagação sobre como doenças incuráveis ou crônicas, deficiência, acidente grave, assassinato, morte em condições dramáticas são vividas por adultos (sobretudo mulheres) que se encarregam do cuidado de crianças altamente dependentes. O material etnográfico é apresentado sob a forma de cenas, de modo que o leitor se depara vividamente com a complexidade, as singularidades, a delicadeza, as nuances, o aspecto trágico e as incoerências das situações.

"Sua filha está se tornando um vegetal", disse a enfermeira a Darlene, mãe de Arlene. "Tudo bem, então nós vamos nos tornar seu jardim", respondeu a mãe (: 176). Arlene é uma bebê que nasceu com espinha bífida, um tipo de malformação grave, e permaneceu internada por vinte e dois meses, período bastante superior às previsões médicas, ao longo do qual foi submetida a cerca de 30 cirurgias, por insistência dos pais, tornando-se completamente dependente de aparelhos e remédios. A metáfora do vegetal, apresentada nesta cena, que é trabalhada mais de perto no capítulo 7, "Tradições morais rivais e o bebê milagroso", é analisada como expressão de duas teorias antagônicas sobre o "humano", mobilizadas pelos pais da bebê e pela equipe médica, no cotidiano de uma UTI neonatal em Los
1 O primeiro resultado de fôlego foi The Paradox of Hope: Journeys Through a Clinical Borderland. Oakland, University of California Press, 2010. 
Angeles. Enquanto a metáfora biomédica do vegetal era empregada pela equipe como prova de que Arlene estava deixando de ser humana, para seus pais, católicos convictos, a metáfora implicava uma transformação moral pessoal a fim de que pudessem prover o cuidado de que ela necessitava. Mattingly busca inspiração em teóricos neo-aristotélicos para tratar ambas as posturas como correlatas de duas teorias morais distintas, a religiosa e a biomédica.

Em sua leitura dessa história, a autora levanta questões "em primeira pessoa", da perspectiva dos pais: como os poderes morais e a agência de Arlene Ihe conferem um "eu" e um estatuto humano que os pais consideram irrefutável, apesar das colocações divergentes dos médicos? Como a justificativa moral dos pais para não desligar os aparelhos que a mantêm viva reflete um projeto de cuidado e um experimento moral no interior de seus próprios projetos de transformação pessoal? Mattingly propõe que os pais da bebê doente inserem a atuação dos médicos num horizonte cosmológico mais amplo concernente à vida humana, que seria regida por Deus. Eles acreditam que as práticas médicas devem ser combinadas a práticas espirituais (rezar, ler a Bíblia, ir à igreja) para se obter saúde e bem-estar, percebendo-se como sujeitos de cuidado ativos, que atuam em relação de complementaridade com a biomedicina. Além disso, os pais pretendiam provocar uma transformação moral nos profissionais que compunham a equipe da UTI neonatal, para que estes deixassem de ser arrogantes e reconhecessem que a vida de Arlene não estava em suas mãos, mas que eles deveriam fazer tudo que estivesse a seu alcance em nome da sobrevivência dela, enquanto aguardavam a manifestação dos planos divinos. De sua parte, os médicos acreditavam que esses pais eram egoístas e que a vida da criança dependia somente da medicina. Os conflitos entre as narrativas dos pais e dos profissionais de saúde exprimem um pluralismo moral que deita raízes tão profundas na sociedade norte-americana que parecem indicar uma cisão ontológica, obstruindo qualquer tradução fácil entre os dois vocabulários.

Ao tratar a situação como evidência de uma incomensurabilidade moral, Mattingly se concentra na força política do discurso religioso proferido por esses pais, que, de forma criativa, inserem as metáforas clínicas num enunciado profético. Ela descreve outra cena impactante, na qual Darlene lhe apresenta sua filha pela primeira vez, na maca da UTI, indicando detalhadamente todas as máquinas, remédios e fios ao seu redor como elementos constitutivos da criança. Ao proceder dessa maneira, a mãe estaria alterando o olhar canônico, redesenhando os contornos do corpo da sua filha, "naturalizando" a tecnologia num corpo milagroso que pode incluir todos os artefatos que Deus ajudou os doutores a criar (: 177). Essa história revela o caráter fundamentalmente relacional do self, uma vez que a doença, a tragédia pessoal e a morte são experimentadas intersubjetivamente. Em síntese, esta é uma história sobre sobrevivência 
e florescimento (um conceito aristotélico) ou, ainda, sobre as conexões culturais entre a ideia de destino inexorável, sofrimento intenso e esperança.

Neste livro, o hospital é pensado como um laboratório moral, assim como a casa, as ruas, a igreja, a escola, locais comuns onde são realizados experimentos cotidianos de cuidado. A partir deste conceito, que dá nome à obra, a autora focaliza os eventos narrativos e a maneira como eles são corporificados pelas pessoas para acessar o aspecto propriamente moral da experiência. A leitura propicia que percebamos que pequenos momentos e atividades rotineiras, como as cenas envolvendo Arlene, o "bebê milagroso", quando observados ao longo do tempo, adquirem profundidade enquanto episódios de narrativas de esforço moral e enquanto parte de um compromisso consciente de efetivar versões particulares de bem viver.

Nos laboratórios morais de Mattingly não há cobaias propriamente: os experimentos são conduzidos por pessoas que têm vínculos próximos com aqueles que sofrem, isto é, "pesquisadores" e "pesquisados" estão todos completamente enredados na situação e anseiam por um desfecho favorável, no interior de um universo de possibilidades em alguma medida aberto para a contingência. Contra a presunção de onipotência do indivíduo autossuficiente que informa certas ideias e imagens ocidentais sobre o sujeito e as relações sociais, e que corresponde ao conhecimento objetificado da ciência moderna, Mattingly defende que a vida humana é um compromisso precário entre as forças que moldaram o passado e as possibilidades atribuídas a um futuro inacabado, um empreendimento frágil, arriscado, em alguma medida incontrolável, tal qual o jardim, espaço que requer cultivo diário.

A obra situa-se, portanto, no terreno da ética, conceito empregado pela autora como sinônimo de moral. De acordo com Mattingly, as complexidades morais envolvidas no "cuidado dos outros íntimos" em circunstâncias adversas requerem um raciocínio multifacetado que engendra contínuas deliberações morais, avaliações e experimentos sobre como viver. Ela pretende compreender como as pessoas confrontadas com dilemas morais dilacerantes tomam suas decisões e assumem as consequências de seus atos. Sob tal perspectiva, o sofrimento dá ensejo a responsabilidades morais, sendo que o árduo trabalho do cuidado implica o cultivo de virtudes pessoais como a compaixão, a coragem e a abnegação, bem como a criação de comunidades de cuidado, que podem incluir a família extensa, vizinhos, amigos e profissionais da saúde. Para a autora, que mantém uma conversação profícua com a antropóloga Veena Das, este "engenho moral" da vida cotidiana, que pode soar antiquado para audiências entusiastas do pós-humano, ilumina a interdependência necessária entre os seres humanos - afinal, ela pondera, como seres humanos simplesmente não podemos existir individual ou coletivamente sem sermos, em alguns momentos da vida, o centro de projetos de base (ou ground 
projects, expressão cunhada por B. Williams) para outros significativos.

$O$ trabalho de Mattingly inspira-se no pensamento de Martin Heidegger, que elaborou, no início do século XX, uma nova leitura da obra de Aristóteles, influenciando pensadores ligados à fenomenologia, à hermenêutica e ao existencialismo, na qual propõe que a ontologia se realiza na prática cotidiana e na temporalidade da transformação humana. No Prólogo, a autora esclarece que há leituras diferentes sobre a fenomenologia de Heidegger e que sua abordagem se apoia na leitura oferecida por Charles Taylor, que se concentra na moral a partir da perspectiva da experiência, configurando-se uma densa fenomenologia da ação em primeira pessoa: "Nós somos animais que se autointerpretam" (: 13), afirma ela, compreendendo o "significado" como um termo necessariamente moral, porque assentado sobre uma orientação para o bem. Seguindo Taylor, ela assume que o self dialógico, não-cristalizado, implica redes de interlocução, em contraste com o individualismo e o construcionismo social, e destaca que a comunidade fundamentalmente provê espaços de conversação sobre os problemas enfrentados pelas pessoas.

A autora esclarece que Taylor e filósofos como Alasdaire Maclntyre, Bernard Williams, Martha Nussbaum, Hannah Arendt, Iris Murdoch e Stanley Cavell, com os quais ela dialoga, buscaram inspiração em Aristóteles para se contrapor à deontologia e ao utilitarismo, predominantes na teoria social em meados do século XX. O ponto que ela enfatiza é o de que esses pensadores atribuem importância a uma concepção de selfculturalmente densa:

Este agente moral repleto de conteúdo e psicologicamente complexo está firmemente situado em cenários culturais e históricos particulares, um panorama que contrasta bastante com o agente moral separado e universal associado aos esquemas morais modernos (:38).

Significativamente, para esse movimento de redescoberta da ética da virtude - que deve muito a filósofas e pensadoras simpatizantes do feminismo-, o cuidado do outro e a esfera doméstica das relações familiares e íntimas são considerados ícones dos desafios e complexidades da vida moral.

O foco das reflexões da autora recai sobre uma ética do cuidado que privilegia um self previamente conectado com outros significativos (o "eu" existe na relação com um "nós" intersubjetivo precedente), em vez de um self autônomo, enfatizando-se as responsabilidades, as relações, a intersubjetividade e o caráter circunstancial da ética, mais que regras gerais e abstratas. Essa modalidade de pensamento ecoa uma sensibilidade pré-moderna, na qual as pessoas são consideradas criaturas sociais vulneráveis, que dependem de circunstâncias que frequentemente escapam ao controle do agente moral singular, e está associada 
ao sentido de uma ordem superior, além ou acima da vida humana, que abrange a dimensão espiritual da existência.

Mattingly sublinha que o pensamento neo-aristotélico se fundamenta no pressuposto de que a existência humana não é um dado, mas um processo que envolve potência e possibilidades. Cultivar a virtude é parte do processo de vir a ser, que se realiza na práxis, no qual a ação virtuosa consiste em um fim em si. Esta corrente de pensamento pretende revisar preceitos básicos que se tornaram parte da reação aos esquemas morais do Iluminismo, mas que não teriam permitido formular enunciados satisfatórios sobre a dicotomia central entre morais locais e liberdades individuais.

Mattingly dialoga com a obra de Michel Foucault, mas inspira-se claramente nos insights de Hannah Arendt (para quem as ações são ilimitadas porque as consequências possíveis são infinitas) e Ernst Bloch (para quem o "real" é um processo inacabado que faz a mediação entre o presente, o passado inacabado e os futuros possíveis). Para a autora, o caráter aberto da ação não pode ser contido por qualquer lei, instituição, pessoa (legislador), sistema ou estrutura social. Ao privilegiar a dimensão da experiência ("ética em primeira pessoa") e o self temporal, Mattingly convoca a abordagem etnográfica e a própria fenomenologia a assumir seu valor propriamente heurístico, demonstrando, por meio de sua etnografia criativa, que a singularidade, a riqueza e a sutileza da realidade apreendidas pelo antropólogo em campo efetivamente desafiam e desestabilizam a teoria, ampliando os horizontes do pensamento social.

A autora (assim como, aparentemente, seus interlocutores) não se pergunta como ou por que a "má sorte" acontece, mas antes que tipos de deveres morais ela prescreve para as pessoas. Ela assume que o processo de transformação moral é lento, pois requer a mudança da percepção em si, o advento de uma nova forma de enxergar as situações e de enxergar a si mesmo (uma "reorientação moral", nas palavras de Murdoch). Desse modo, Mattingly focaliza, sobretudo, o jogo entre o trabalho interior e o mundo da ação social, algo mais externo, mais intersubjetivo, dialogando com Thomas Csordas. $\mathrm{O}$ trabalho de transformação pessoal analisado não diz respeito apenas a projetos de aprimoramento pessoal, mas demanda uma mudança no mundo. As pessoas reconhecem que o cuidado dos sujeitos próximos implica negociação, problematização e por vezes confronto direto com as instituições e seu modo especializado de cuidado ou com os modos de cuidado característicos da vida comunitária cotidiana. Esta forma de encarar os momentos dramáticos de experimentação do cuidado permite contemplar a incerteza e a contingência, afastando a repetição automática do passado e possibilitando pequenas, mas significativas, revoluções na esfera do cotidiano. Olhar para as histórias quase invisíveis que se passam nos laboratórios morais, trazendo à luz esforços que 
poderiam permanecer despercebidos, faz com que o ordinário seja visto como o espaço no qual algo novo pode ser criado, ainda que suas consequências sejam frágeis e imprevisíveis.

É digno de nota que as e os protagonistas dessas histórias com " $h$ " minúsculo (ou "experimentos inacabados") não aceitem o destino de forma passiva, não se acomodem na posição de vítimas - ainda que sofram os efeitos de uma situação de desigualdade pervasiva, decorrente de uma estrutura econômica injusta e do racismo estrutural que marcam a sociedade norte-americana. Eles demonstram habilidade para formular um desafio a um discurso normativo, por meio da justaposição crítica da experiência vivida. Olhar para o potencial trágico dos projetos pessoais de transformação, descortinar a enormidade da tarefa de realizar sonhos morais ou a tragédia da incomensurabilidade moral, ajuda a revelar onde se localizam os obstáculos para a transformação e permite que se aja sobre eles de forma mais ou menos eficaz. Mattingly assume que o sofrimento geralmente engendra reflexão, experimentação e mudança, mas conclui seu experimento narrativo com uma história particularmente triste, aquiescendo com a ambiguidade fundante da experiência, postulada por uma longa tradição filosófica, de acordo com a qual o "sujeito que sofre" e o "sujeito que se esforça moralmente" são componentes inseparáveis da condição humana.

Ao lançar a provocação sobre a vocação filosófica da antropologia, por meio da reflexão sobre outras práticas de cuidado que não as dominantes, Mattingly parece ter sido contaminada pela concepção de bem viver de seus interlocutores e, assim, o livro é impregnado de sabedoria, outro conceito empregado por Aristóteles, que se diferencia da inteligência livresca ao agregar a experiência pessoal do aprendizado prático à virtude moral. Ainda que se possam levantar questionamentos pertinentes sobre o possível efeito de reificação de estereótipos de raça e da capacidade de superação associada a grupos subalternos, o livro é tocante, sensível e faz pensar sobre diferentes modalidades de cuidado e concepções de saúde e bem-estar, que florescem contra toda estatística, um instrumental heurístico de ponta para inspirar reflexões vicejantes em antropologia da saúde, bioética, psicologia social e canteiros disciplinares afins.

Giovana Acacia Tempesta é pesquisadora-colaboradora plena vinculada ao PPCAS/DAN/UnB e atualmente desenvolve pesquisa na área da antropologia do parto. No mestrado e no doutorado realizou pesquisas na área da etnologia indígena, na Amazônia brasileira. 